\title{
Muslims and Medical Ethics: Time to Move Forward by Going Back
}

\author{
Mustafa Ahmed ${ }^{1}$
}

Published online: 4 February 2016

(C) Springer Science+Business Media New York 2016

The study of Islamic medical ethics represents the confluence of many domains, with an emphasis on anthropology, sociology, religious practice, Islamic law and morality. Navigating these waters in the context of an ever-changing medical environment, with advancements reminiscent of what was once considered 'science fiction', requires a multidisciplinary study.

The University of Florida Center for Global Islamic Studies recently sponsored a 1-day symposium examining these issues. This was a multi-faith, multidisciplinary meeting which brought together experts from across the nation, supported by the University of Florida Office of Research, Center for the Humanities, Department of Religion, Center for Spirituality and Health, College of Medicine, and the Florida Bioethics Network as well as the Dr. and Mrs. Sayeed Ahmed Islamic Lecture Series. The following Special Section highlights the themes which were discussed and represents some of the 'next steps' required as we learn to tackle these complex issues.

The need for open and honest dialogue about Islam, bioethics and modern healthcare is of growing importance as the number of American Muslim physicians and Muslims in American society continues to expand. Presently, Muslims make up $2 \%$ of the US population, and 5-10\% of all US physicians. While these numbers can be described as 'small and growing', the religious and cultural heritage of Muslim physicians and patients has a significant impact on interpretations of sickness, wellness, healthcare delivery and acceptance. Moreover, the current sociopolitical issues surrounding Muslims both in the United States and abroad have the potential to create biases in the general population which may creep into the healthcare system, affecting how Muslims and others interface with one another, creating unnecessary barriers to the development of therapeutic relationships. Additionally, minority patient populations, such as Muslim patients, are known to receive lower quality of care and face significant barriers when attempting to interface

Mustafa Ahmed

mustafa.ahmed@medicine.ufl.edu

1 University of Florida, Gainesville, FL, USA 
with the increasingly complex healthcare system. Therefore, studying Islam in the context of modern medical bioethics is a step to further understand Muslims as patients and providers, and how their experiences may inform a broader study of bioethics. Additionally, increasing awareness of Islamic medical ethics would allow for a more culturally competent care and overcome potential barriers that may arise when caring for Muslim patients. Furthermore, this study of Islam and bioethics is of increasing importance in our current healthcare model as we move from paternalism to partnership.

Although the precise role each of us can play in this process remains to be determined, it is clear that there are unmet needs. As an American Muslim physician, I am often requested to exchange my white coat for the garb of one who provides spiritual support and ethical guidance to patients and those charged with their care. My credentials for offering such assistance resides more in my religious and cultural identity as opposed to specialized training. My experience is the norm rather than the exception. Recent data from the Institute for Social Policy and Understanding examining chaplaincy services in New York City demonstrated only 10 identified Muslim chaplains in a survey of 56 pastoral care directors. This likely represents a base case scenario and, when taken in the context of New York city's Muslim population-estimated at anywhere between 600,000 and 1 million, with $10 \%$ of all public school enrollees self-identified as Muslim-we see the substrate for a lack of culturally competent care and potential for the creation of faith-based healthcare disparities. While reliance on local imams and religious leaders to provide spiritual support and aid in complex ethical discussions is often the default contingency, these individuals may be ill-prepared to take on this task, and many are over-burdened to properly engage with patients and providers. Therefore, clinicians, who themselves may lack appropriate religious or social training, are thrust into the forefront, not simply as participants, but often as the de facto Muslim leaders of this aspect of care. The necessity to enhance our educational directives and support for such individuals, both imams and these 'clinician facilitators', to create a general awareness and competency is therefore of vital importance.

Partly, the challenge in doing so while addressing nuances of Islamic medical ethics resides in the ethnic and cultural diversity of Muslims and the inherent legal plurality of Islamic jurisprudence. Coupled with the lack of an ecclesiastical hierarchy, this imposes an added dimension of both complexity and tone to understanding these theoretical issues in the often too real context of one patient. Perhaps the key to addressing such complexities is to build from awareness and cultural competency to develop forums wherein all the major stakeholders can participate in discussion. This would include patients, healthcare providers, as well as religious scholars and spiritual leaders. Only in this multidisciplinary and multi-faith fashion can we create an appropriate model for understanding Islamic medical ethics which can then refine bioethical practice.

The legacy of Islamic medicine is one of scientific advancement, holistic healing and community service. Unfortunately, it is a legacy which is all too often neglected or forgotten with the tremendous difficulties in the current sociopolitical environment. At this moment in our collective histories, we must return to that great legacy in order to quiet those angry voices who threaten to distort and destroy that which was so carefully crafted over centuries. Explorations and discussions, such as those which follow, can be one step in that direction, and start the healing of both body and spirit. 